\title{
The cultural turn in Community Interpreting. A brief analysis of epistemological developments in Community Interpreting literature in the light of paradigm changes in the humanities
}

\author{
Mette Rudvin \\ University of Bologna
}

This essay traces some of the major epistemological shifts in the humanities over the last century, in particular anthropology, which have informed and profoundly altered language- and literary disciplines in Western academia, especially those relating to the subjectivity of the observer (the anthropological 'gaze'), the complex interconnectedness of language and the surrounding socio-cultural network, the ephemeral nature of language itself, and the issue of textual authorship-ownership. This paper attempts to put into relief the interface of philosophical issues that arises as a result of these paradigmatic shifts with practical issues of professional ethics and role-definition in community interpreting. The paper also attempts to show that what emerged in translation studies as the 'cultural turn' has already taken place in community interpreting (not necessarily across the board in other forms of interpreting) due both to influences from other related domains and to the specific cross-cultural nature of community interpreting itself.

\section{Introduction}

Community Interpreting today has moved from a largely prescriptive approach with an almost exclusive focus on issues that embody a monolithic view of language in which the interpreter is seen as 'a pane of glass' or a 'black box' through which ideas flow unchanged. Today, in both research and practice, there is an increasing appreciation among scholars and practitioners in the field of the fact that language - and thus the interpreter's performance - is a much more complex, interactive affair situated in a larger institutional, cultural and 'political' framework that affects both micro- and macro-linguistic aspects of the interpreter's performance and of the various interlocutors' utterances. The appreciation that the interpreter-mediated exchange is constructed by all (3) parties together, and governed by external rather than only internal factors, has deeply affected the understanding of the interpreter's role. The broadening of issues addressed in the literature on community interpreting (hereafter CI) also reflects this development: from an insistence on terminology/correspondence, on prescriptive-style training programmes and equally prescriptive Codes of Ethics presented to a lesser or greater degree as 'rules' for the interpreter, CI literature today includes a wide variety of studies on issues. These issues include comparative cross- 
cultural aspects; descriptive case studies; institutional constraints, political agendas and ideology; the specific constraints of the various fields in which $\mathrm{CI}$ is applied and resulting differences in the understanding of the interpreter's task; interpreter alignment through talk coordination; interpreter participation; power relations in the interpreter-mediated exchange; and not least the complexity of the interpreter's role as a result of all of these socio-cultural variables. Not surprisingly, however, this evolution has made itself felt much more strongly in academic research than in professional organizations and training institutions where the monolithic approach to language is still common, if not predominant.

I would like to start this paper by describing some of the major paradigm shifts in Western academia in order to position the current state of the art in CI within this general framework. From the rationalist, unified absolutes of grand theories through the functionalist analysis of the interaction of systems, institutions and practices, mainstream Western academia has moved to a more interdisciplinary interpretative/narrative approach in which a reassessment of ideas has redirected and repositioned earlier assumptions. The vast quantity of literature across disciplines that both describes and employs these paradigm shifts is too wide-ranging to describe or even refer to in any encompassing manner. To maintain a reasonably tight focus in this brief essay, I have chosen to use two texts by Wagner and Marcus \& Fischer as a guiding framework, excluding thus a range of seminal studies in other related disciplines (in particular literary criticism, cultural studies and sociology). The two books are sufficiently synthetic as descriptive analyses for the purposes of this paper as well as being representative of the moment in which this shift was beginning to permeate the humanities (1975 and 1986 - spanning the highly productive decade of the mid 70 s to mid-80s). They also represent the seminal contribution of their discipline - cultural anthropology - to the humanities. Both texts capture succinctly the mood and the essence of the 'cultural turn' and locate academic developments in a wide historical and disciplinary perspective. The resulting disciplinary bias is inevitable but compensated for, I believe, by the fact that they provide a broad description of the epistemological undercurrents, as it were, of basic developments in the humanities during the last half-century and more. Another, equally profitable, approach to this essay would have been to look at the related and contemporary paradigm shifts in literary criticism, the main locus of literary studies from the 1980s onwards and, in particular semiotics, reader-response theory, deconstruction and postcolonial studies. Since these approaches postdate the new trends in anthropology, however, and are arguably spin-offs from developments in anthropology and sociology, I have chosen to focus on anthropology rather than literary studies or the more recent, highly eclectic field of cultural studies. This seems even more appropriate given the fact that cross-cultural analysis is the base-line methodology and objective in both CI and anthropological research.

There are four aspects of these paradigmatic challenges which specifically engage our discipline, namely: the dynamic nature of language; the 
pervasiveness of culture; the role of culture as a network of systems interacting with each other institutionally and between system/institution and individual (on both vertical and horizontal axes); and the role of the researcher/practitioner. All of these issues will be touched upon in the course of the essay.

\subsection{Premises. Epistemological developments and paradigm shifts in the humanities}

As mentioned a general re-evaluation of culture as an underlying factor in all social practices lies at the heart of these developments, and therefore also a re-evaluation of the definition and nature of the notion of 'culture' itself. In addition to this, there are two basic changes that embody the most salient and the most pertinent features of paradigmatic shifts in Western academia from the 1960s onwards. The first is a gradual abandoning of the classical rationalist's absolute objectivity within the framework of all-encompassing 'grand theories' to a culturally relativistic approach in which all cultures have equal weight. Instead of constructing grand theories, researchers today tend to examine local realities. In other words, what we see is a shift from unitary theories to multi-voiced representations. No longer considered to be adequate tools with which to describe what was increasingly understood as an ephemeral reality, grand theories were left in 'suspension' in what Marcus \& Fischer argue is still a period of transition 'in between' new paradigms. ${ }^{1}$ The discovery that the theories themselves were not only inadequate but also partial and ideological, led to the acknowledgement that the description and representation of these theories were also ephemeral and partial. ${ }^{2}$ Through smaller-scale ethnographic case studies (already part and parcel of the anthropological tradition) social phenomena were reconstructed from the bottom up rather than top-down, as was the case earlier (see Marcus \& Fischer 1986: x).

The second, interconnected aspect of the paradigm shift is a crisis of representation deriving from a more nuanced understanding of the role of the researcher/observer (Marcus \& Fischer 1986: 8). Because of the nature of the discipline and its research methodology (ranging historically from ethnographic description to general theories and cross-cultural comparison), anthropology was one of the earliest fields to position the critic in relation to that which is critiqued (see ibid.: 115): no longer a detached, neutral observer, but a participating agent whose Self is constitutive of the very text $\mathrm{s} / \mathrm{he}$ is constructing. Ethnography is thus acknowledged to be a highly personal and imaginative process (an anthropologist experiences the object of his study; Wagner 1975: 3). The researcher has thus moved from being an objective detached scientist studying the behaviour of people(s) to being a cultural interpreter. An awareness of the lack of an adequate means of describing social reality objectively, led to an acute awareness of the difficulty of representing cultural difference, which perfectly matched the emerging 
relativistic approach. In other words, problems of description become problems of representation.

The awareness of the scientific/academic text as a 'representation' of the individual scholar's subjective interpretation - both in content and in form - thus led to a profound awareness of form itself: the "explicit discourse that reflects on the doing and writing of ethnography itself" (Marcus \& Fischer 1986: 16). Because of the importance of form (the text production process itself, not just the finished product), narrative studies and particularly critical literary theory took up the challenge from anthropology. Anthropology and literary criticism are thus both 'exemplars' in the context of this paradigm shift, anthropology in particular serving "as a conduit for the diffusion of ideas and methods from one to another" (ibid.: 16). ${ }^{3}$ These changes in research methodology led to a focus on methodology itself, on epistemology, discursive forms and particularly interpretation (i.e. the meaning of 'meaning', the complexity of subjective and objective points of view, of absolute values and neutrality versus relative values, ideas and relationships).

One of the results of the crisis of representation and of the proliferation of these focussed, local studies that supplanted the run of grand theories was to generate a sense of critical self-reflection towards the writer-researcher's own culture through a process of 'defamiliarization', by challenging and 'disassembling' what once seemed 'natural' and immutable to the researcher (Marcus \& Fischer 1986: 127).

\section{2. 'Defamiliarization' and conventionalized shared knowledge}

Understanding society, culture, language, other individuals, indeed meaning itself, is only possible if there is some basis of shared meaning in each group and in each unit of what we call 'culture'. It is the very conventionalising of that system of signs that allows us to communicate through verbal language and other semiotic systems to create what we understand as 'meaning'. And it is only through such shared conventions of his/her own culture(s), Wagner argues, that the subject can relate to and construct or 'invent' his/her interpretation of another culture (Wagner 1975: 39ff). As the individual is being socialized into a particular community, society or culture, these shared conventions appear 'natural', immutable, self-evident, fully familiar and thus in some way 'invisible'. Wagner argues that "the idea that some of the recognized contexts in a culture are "basic" or "primary", or represent the "innate", or that their properties are somehow essentially objective or real, is a cultural illusion. Yet it is a necessary illusion" (ibid.: 41). In other words, one could argue that an emic (insider's) perspective is necessary in order to construct an etic (outsider's) one. Breaking this 'familiarity', making visible the self-evident, is achieved through comparison with the/an 'Other', be it an individual or a group. (Indeed, one might argue that this mirrors a basic process of socialization of children as they discover the world outside themselves). The anthropolo- 
gist/researcher realizes the relative character of his own culture through concrete formulation of another and thus, in Wagner's words, 'invents' another culture (ibid.: $2 \mathrm{ff}$ and $37 \mathrm{ff}$ ): The culture in which one grows up in is assumed, invisible, self-evident and is only made visible and manifest through comparison with another. Thus, ethnographic research as the ultimate close study of the 'Other', pursued in various forms in many disciplines, is quintessentially 'a journey of self-discovery' (ibid.). Cross-cultural juxtaposition thus also became a tool of critique of Western society (Marcus \& Fischer 1986: 20). Consequently, the rationale for research becomes that of generating inquiry about one's own culture and norms. One of the spinoffs of this approach is that difference and diversity are valorized (ibid.: 111-112) rather than seen as intrinsic weaknesses, a notion that plays a major role in the (sub-)disciplines of literary criticism and postcolonial studies that were to follow in the subsequent decades, permeated by a sometimes obsessive rhetoric of the celebration of 'difference'.

\subsection{Interdisciplinarity}

Feeding into the various movements and shifts in late- $20^{\text {th }}$ century academia we find a vibrant and fluid borrowing of ideas across disciplines (Marcus \& Fischer 1986: 7). Whilst anthropology borrowed from linguistics in the early 1950s and 1960s in an attempt to define general theories through an appealing formal rigorous framework for generalizing 'descriptive science', Marcus \& Fischer note that by the 1970s-1980s the interface language/anthropology is found primarily in critical literary theory, especially in Barthes, Derrida and later Said (especially in his work on the rhetorical representation of other cultural objects in narrative). A decade later, it was flourishing in the emerging discipline known as cultural studies. There are two prongs, then, in this paradigmatic move, embodied in those fields that are most closely tied to observing and explaining social phenomena in the process of change and to genres of description through narration and representation. ${ }^{4}$

These fields, then, are at the forefront in challenging the reigning paradigms, indeed the very idea of 'paradigm' itself (ibid.: 5 and 15). What we are experiencing now, Marcus \& Fischer say, is a diversity of fragmented research programmes (ibid.: 5), a transitional period between more settled paradigmatic periods of research in which newer interpretative paradigms are challenging old positivist ones. They warn, however, that "[t]o still pose one paradigm against the other is to miss the essential characteristic of the moment as an exhaustion with a paradigmatic style of discourse altogether" (ibid.: $\mathrm{x}$ ); indeed the shift is a result of a suspicion of all totalizing styles of knowledge. Many of these ideas are already contained in the work of Bakhtin, of course, writing in the 1920s, whose work was foundational to the Russian Formalists. Bakhtin demonstrated that text production is a dynamic, dialogic affair, that the text is ideologically loaded in itself and in its interaction with and function in society - in other words, in 
its wider context. The concept of heteroglossia (the text as containing many 'voices') should have put to rest once and for all any misconceptions about the monolithic nature of language. And yet it did not, or in any case not until much later.

\subsection{The nature of language}

Given that language is at the heart of linguistic and literary studies, indeed both the object of study and tool of that selfsame analysis, it is important to understand the wider, global shifts in how language is viewed as a representation of human thought and action and as constitutive (in a Sapir-Whorfian approach) of that same human thought and action. In translation and interpreting (both as professions and as academic disciplines) the importance of language is perhaps even more evident: the concrete use of language in its communicative function (and the need for communication to be effective) intersects the trajectory of institutional language use, social and ethnic varieties of language as well as cultural, pragmatic and kinesic aspects of language use. It is at this intersection - distilled in the practitioner's global language competence and ability to 'perform' language polyphonically (in two or more languages) - that the translator/interpreter is useful to society. So shifts in how academia views language globally - shifts that will eventually impact to a smaller or larger and not always predictable degree on the professional domain - deeply affect the service that interpreters and translators provide for society.

In the same way that views on culture have increasingly valued and emphasised the more (diachronically and synchronically) dynamic and inter-related aspects of culture, and the subjective and relativist nature of the phenomenon of observing and describing culture ('representation'), there has been a trend towards valuing the social, pragmatic, dynamic and inter-related aspects of language as a cultural and social system in a larger context rather than as a code accountable only to itself and suspended in space, as it were. As Wagner says: "The conventions of language become meaningful only when they enter into relations of objectification with some observed or imagined context" (Wagner 1975: 106) and a few pages further on: "The conventions of language are always to some extent relative, for as an element in the ongoing invention of the world, language itself is always in the process of being invented." (ibid.: 109). The study of language as a linguistic, philological formal code, as an objective, given reality was, despite Bakhtin, the basis of many linguists' conception of language in the early to mid $20^{\text {th }}$ century. (There are some important exceptions to this rather narrow understanding of the function of language - notably Whorf and Sapir.) Today, however, it would be safe to say, at least in Western academia, that language is seen as a set of ideological tools and relationships; as Wagner says, we invent reality through conscious use of language (ibid:: $107 \mathrm{ff})$ "(...) for language can exist no more outside of the emotional and creative situations of human life than culture can." (ibid.: 113). ${ }^{5}$ 


\section{Language studies}

Contemporaneously with the shift from absolute, all-encompassing grand theories to micro-level analyses highlighting contradictions, paradoxes, differences and exceptions, we find a gradual change in the understanding of language from an absolute, immutable system pertaining exclusively to one nation/group (a residue of the European National-Romantic philosophy) or a self-contained system (Chomsky) in which a neutral all-inclusive channel of expression is able to reflect and express any social, mental or institutional thought/phenomena, to a more dynamic and critical approach in which the contextual factors of society, culture, ideology, politics, institutional frameworks, technology and the media impact on languages and place constraints upon language usage. ${ }^{6}$ Inherent in this shift is a change from ideologically marked prescriptive standard-setting attitudes (i.e. the imperative use of a middle-class British English in English language teaching worldwide in which institutions such as the BBC, the British Council and OUP were dominant actors) to an appreciation of variations in language use and descriptive research methodology. The subsequent shift is already contained in the new nomenclature from that period, i.e. from linguistics and philology to language in context: semiotics, socio-linguistics, critical discourse analysis, anthropological linguistics, pragmatics, global English, etc. (represented by scholars such as Peirce, Fairclough, Labov, Lakoff, Hymes, Goffman, Goodwin, Duranti, Gumperz, etc.). One of the areas in which the general shift is most evident is in what has come to be known as the ethnography of communication. The task of the ethnography of communication is precisely that of elucidating communication conventions in various societies and to understand the dynamics of reflection and representation by cross-cultural juxtaposition (as mentioned above, the quintessential nature of ethnographic research methodology). According to Saville-Troike, this branch of language studies

lies at the intersection of linguistics and anthropology, sociology and hermeneutics, folklore and political science, speech and social psychology (...). As Hymes has pointed out, the traditional focus of linguistics on abstract code characteristics to the neglect of function, and the traditional focus of anthropology and sociology on the abstract patterns of cultural and social organization to the neglect of details of their enactment, has left us largely ignorant of the role of language and other modes of communication in the realization of social life. (Saville-Troike 1982: 249) 


\subsection{Sibling disciplines. Translation studies}

As most other branches of language studies, Translation Studies too has undergone a significant, even dramatic, epistemological shift in methodology, research aims and scope. As a result, the text (ST, TT) has been repositioned in a larger political, ideological, cultural and social arena, perfectly in line with the situation that has been described above. During the 1950s-1970s then, the emerging discipline of TS mirrored the larger foundational premises in other branches of language studies, especially linguistics, from which one might say it partly derived. The persistent focus on relations of equivalence and faithfulness, from Catford through Nida to Newmark, presupposed a model of language as a neutral, self-contained vehicle functioning within a framework of an unchanging system or set of systems, and a monolithic view both of the speaking/writing subject and his/her interpersonal relationship with the interlocutors. This, again, was in perfect harmony with the 'grand theory' stage described above in which universals are accepted as monolithic entities (the exception being literary translation, not surprisingly). In my view, although Nida no doubt fits into the 'grand theories' phase (not least for reasons of his own personal religious convictions as a Bible scholar), his work was nonetheless a significant breakthrough in the process of repositioning the text in terms of its function in a larger context (cf. his resulting model of dynamic equivalence). Indeed, we could call Nida's an anthropologically functionalist viewpoint; he thus precedes the equally functionalist and highly context-based work of the German scholar Vermeer in the 1980s. Inherent in Vermeer's 'skopos' was a re-positioning and re-evaluation of the nature and the function of the translated text (as much as the later and more frequently quoted descriptive frameworks of 'rewriting', see Shlesinger \& Pöchhacker (2002) and Venuti (2004). The 1980s also saw the publication of Toury's (1995) ground-breaking normbased descriptive model based on Even-Zohar's polysystem theory, a contribution which constituted a true paradigmatic change - in a strong sense of the word - within TS. ${ }^{7}$ Not only did Toury introduce the notion of norms, the notion of the adequacy-acceptability continuum (not as an either/or choice as it is often represented), the notion of market forces and historical and ideological forces impacting on the translation of the text and its selection (i.e. a general target orientation), but by focussing on translation as what the target culture understood a translation to be rather than what - ontologically - constitutes translation per se as an absolute value and/or definition, he broke the stale-mate with previous epistemological premises that was leading the discipline nowhere. He thus managed to introduce the most salient factors in the general paradigm shift, essentially putting the text back into context. At the same time he side-steps the absolutist trap of equivalence and fidelity, to which there is in fact no 'answer' or 'solution', given both the ephemeral and culture-bound nature of language. The full impact of this paradigmatic shift, perfectly in line with the broader shifts described above, has perhaps still not been fully appreciated. Alongside this deep shift in focus and methodology, the emergence of culture - in the widest sense of 
the word both as ethnic- and institutional ideologically-loaded culture - as a pervasive force in the production, translation, publishing, marketing and reception of texts began to take hold. There is now an increasing appreciation in TS of context as being constructed by the observer (as in the anthropological 'gaze'). The move from grand linguistic theories and equivalences/correspondences to an interactional and functional view of language via a target-oriented context-based polysystem network theory was a natural precursor and possibly a prerequisite to current trends in TS, particularly social constructivism, network studies, and postcolonial studies. $^{8}$

It is commonly accepted today that translation is not an 'innocent', neutral practice but rather an open bidirectional channel of communication and meaning. Much has been made of the issue of overt/covert manipulation and rewriting as a metaphor and/or synonym for translation. This is clearly a result of larger paradigmatic changes in language studies. The ensuing tug-of-war between ST fidelity and TT efficaciousness has, of course, raised a host of ethical questions and a great deal of debate in the discipline as well as a certain amount of friction between practitioners and theorists. Does the implicit message in recent translation theory constitute a 'free-forall' poetic license? And if so, is this message confusing to translation practitioners and to primary text authors, one might ask. How does current TS accommodate issues of authorship, intellectual property and intellectual ownership and to what extent are the author's rights safe-guarded if translation practitioners feel that current theory gives them free reign to rewrite and manipulate? Paradoxically, these new insights deriving from wider paradigmatic shifts are as illuminating as they are potentially confusing.

\subsection{Interpreting studies}

Franz Pöchhacker provides a useful account of the shift in paradigms in Interpreting Studies (hereafter IS) in his book Introduction to Interpreting Studies (ch.4), to which the reader is referred for further detail. It is important, I think, that Pöchhacker considers interpreting to be a form of translation and as such identifies the basic common denominator as language transfer generally rather than the mode of transfer (written/oral). The fact that Pöchhacker does not differentiate between conference interpreting and $\mathrm{CI}$, and that he naturally brings CI into his book as an integral part of the discipline, is indicative of the fact that there is more that unites these two branches than divides them. He describes how IS moved from being a small, heterogeneous community to achieving academic distinction by the late 1970s, largely thanks to Seleskovitch's interpretative theory of translation. During this time (from the 1960s), the cognitive approach advocated by psycholinguists conducting experimental studies with empirical data "... could be said to have imprinted the field with regards to methodology" (Pöchhacker 2004: 69). A decade of descriptive, empirical studies aiming at high scientific standards followed in the 1980s, championed by researchers 
and practitioners such as Gile, challenging the prescriptive idealization of Seleskovitch's 'Paris School' and taking into account real-life conditions under which conference interpreters work (what Angelelli calls the 'renewal period'; 2004b: 16). Although the emerging cognitive processing paradigm, Pöchhacker comments, shares "the broad agenda of cognitive scientists to explain the interplay of language and cognition" (Pöchhacker 2004: 73; see Shlesinger \& Pöchhacker 2002 for Gile) and although there is a growing sensitivity towards the wider social and professional context, there is still clearly a positivist bias focussing on the mechanical, physiological aspect of language transfer rather than on dialogic processes. In this increasing focus on mental processing activity, many socio-communicative activities were unaccounted for (ibid.: 76). Functionalist approaches such as Vermeer's skopos theory and target oriented approaches (and Pöchhacker's own use of functionalist theories) began to compensate for this lack. Although this trend fits in with and converges with descriptive translation studies (taken up by Shlesinger in IS) and the larger paradigm shift, we cannot yet speak of a paradigm change, Pöchhacker says, despite the occasional voice in the field that calls for a reorientation to take "into account the entire communication process" (Stenzl in Pöchhacker 2004: 77). Today, mainstream IS still lags behind TS in its rather narrow and tendentially monolithic approach to the nature of language and language transfer. As we will see below, CI has perhaps already surpassed mainstream IS in accommodating recent paradigm shifts. Although some exceptions should be made for the differences in mode and setting, IS could benefit from the new research methods and paradigms embraced by CI scholars.

The widening of IS research over the last decade to include forms of interpreting other than conference interpreting embraces functionalist and interactionist approaches. It might even be argued that the general increase in studies on cross-cultural language transfer, the increasing focus on nonWestern forms of verbal and non-verbal communication, and an increasing target- and context oriented approach could be a result of the powerful emergence of CI during this last decade. I would go so far as to say that CI has had - or rather is in the process of having - a significant impact on the direction IS will take in the future, both in its epistemological basis and for what concerns research methodologies. Thus one might say that CI is prising open the reified boundaries of IS, forcing it to take on board macrostructural aspects relating to the wider social and cultural context, thus greatly enriching the discipline.

\subsection{Language transfer and the new paradigm}

"Rather than semantic quibbling this ['interpret'] constitutes a fundamental challenge to our understanding of what it means to translate and/or interpret" (Pöchhacker 2004: 10). This quote sums up, I believe, the basic underlying issue all translators must grapple with and the difficulty inherent in the practice. Any activity that falls within the wider domain of translation in 
the sense of written and oral language transfer, must necessarily come to terms with what is for the practitioner a paradox, or a 'catch 22' situation. On the one hand $\mathrm{s} /$ he is bound by the authority of the original text and the translator's ethical responsibility towards the primary author's text or utterance (pertaining to the equivalence-fidelity trope). On the other hand the micro-linguistic constraints and general differences between ST and TT do not necessarily permit a rendering of that 'same' message. At the same time, as the new paradigm has highlighted and as translators - being language experts - are keenly aware of, language is a social practice embedded in a complex macro-structural network that places further functional and pragmatic constraints on the possibility of rendering ST into TT in a reasonably similar form and function (dynamic equivalence). Lastly, the translator is embedded in that same network of systems and his/her reading of ST is subject to her private and social position within that network. Any rendering of ST into TT is thus a result of that unique private and at the same time sociocultural reading. To close the circle, however, and herein lies the paradox, the translator is nevertheless bound by her private and professional ethics to produce a text/utterance that reflects what $\mathrm{s} /$ he understands the primary text producer's intention to be in a manner that attempts to recreate that same intention vis-à-vis the receiver. In an oral communicative event this is rendered even more complicated by the interactional components of the event and its 'micro-politics'. Thus, the translator/interpreter is called upon to multi-task, to coordinate the communication situation as well as enacting the process of language transferral. The 'catch 22 ' thus embodies both relativist as well as positivist approaches to language and text - as a fixed point of departure and as a subjective interpretation/cultural representation.

\section{Paradigm shifts in Community Interpreting}

In the short history of the discipline, the literature on community-based interpreting has evolved from a prescriptive approach with a myopic insistence on the 'interpreting is interpreting' trope using equally myopic 'pane of glass' style metaphors denying any visibility to one of the main protagonists and vehicles of the communicative event, to a much more realistic and fuller understanding of the complexities of this event situated in a specific socio-cultural moment, thus perfectly in line with the general movement in language studies described above. (That is not to say that studies from other angles did not exist; training, for example, was a recurrent issue.) Alongside these studies there were also other practical studies describing the situation on the ground, the needs of minority language communities and local scenarios with specific language-related, institutional and political needs (a good example is Erasmus 1999) etc. CI has emerged at a time when the umbrella discipline (itself informed by a general evolution in the humanities and in language and, as described above, literary studies) was ripe to embrace and accept ideas that went far beyond the mechanical and linguistic focus of the positivistic approach a mere decade earlier. One 
of the reasons for this is its unique position at the intersection of many different professions, academic disciplines, corporate and ethnic cultures and, not least, the uniquely private trajectories of each individual interlocutor. Confronted with such a complex network of social practices in the microcosmos of the consulting room, a refugee hearing, a police station, a classroom, the interpreter's performance is severely challenged by the contradicting mandates of the positivist paradigm inherent in the mechanical language transfer model. The demands upon him/her from each of the different professional, academic, cultural and individual strands in that microcosmos, as well as the dialogic nature of the process in which shared 'meaning' emerges, renders any merely mechanical transferral process impossible and yet, paradoxically, at the same time necessary according to the existing Code of Ethics (cf. the 'catch 22' situation described above). One could say that the crux of the paradigm shift lies in this very moment in which the constraints of the monolithic model - in which many of us have been raised and trained - do not coincide with a more realistic and down to earth understanding of the complexities of language and the pragmatic requirements of the communicative event. The frustration of forcing a match between the old and the new paradigms (without necessarily being aware of either) is stress-inducing, to say the least.

\subsection{Recent trends}

The prescriptive approach so prevalent in the early history of CI came to the fore particularly strongly in training programmes, the descriptions of which were frequent in the literature. In the first two chapters of her excellent 2004 study on the role of the conference, court and medical interpreter (to which the reader is referred for a full overview), Angelelli (2004b) describes the development from prescriptive studies to a more realistic, inclusive approach appreciating the complexity of the interpreter's role - using the eloquent metaphor 'breaking up the closed circle'. She notes how the goal of most training programmes in early CI literature was to train interpreters to render the mediated exchange as smoothly as if the parties had a common language: "Training programmes set this unattainable goal as an attainable reality, and as a result, a tension emerges between the prescribed and the actual role of the interpreter" that also distorts the reality of the interpreter's work in practice (ibid.: 13). The divorce between the "prescription and the reality" of interpreter-mediated communication and the insistence on the 'invisibility' of the interpreter is still prevalent among professionals and organizations today, she comments (ibid.: 24).

There are a handful of books that deserve special mention here in that they represent this paradigm change and at the same time, as landmarks in the literature, are consolidating it and setting a precedent for the development of the profession and for future research. Wadensjö's ubiquitously quoted Interpreting as Interaction (1998) comes first to mind, of course, indeed it has been a watershed for CI, bringing together insights from a range of 
seminal scholars (not least Bakhtin) in other fields, and applying these insights to CI and dialogue interpreting more generally. Roy's Interpreting as a Discourse Process (2000), Angelelli's Medical Interpreting and Crosscultural Communication (2004a) and Berk-Seligson's The Bilingual Courtroom: Court Interpreters in the Judicial Process (1990) also deserve mention, although these by no means exhaust the list. The titles of the books that have strongly influenced CI research are in themselves indicative of a general turn towards an interactionist and interactive, more relativist, approach to language and to language transfer (note Metzger's Language Interpreting: Deconstructing the Myth of Neutrality 1999). Ian Mason's 1999 and 2001 discourse based contributions on interpreting and the construction of social identity should also be mentioned. Another angle which has been covered quite extensively in medical interpreting, often through the use of larger or smaller scale surveys (for example Kadric, Pöchhacker and Mesa in Roberts et al. 2000 and Angelli and Chesher et al. in Brunette et. al. 2003) but the list is long; many are to be found in the Critical Link series), is that of interpreter self-reflexiveness: how interpreters view themselves. Such studies clearly embody the self-critical approach of the observer as participant (the anthropological 'gaze') in the general context of representation. Angelelli's work $(2004 \mathrm{a}, \mathrm{b})$ is particularly interesting here in that she demonstrates quantitatively how interpreters struggle with the issue of (non)visibility and how closely tied this issue is to that of role. CI has, unwittingly perhaps, taken up the gauntlet from Vermeer and Nida's functionalist approaches and Toury's descriptive target-oriented approach. Due to the institutional (public service) dimension of CI, several epistemological trajectories are feeding into each other at the same time from various academic disciplines. Thus, individual scholars are applying findings and input from anthropology, sociology, law or medicine to language studies and interactional communication. We find, thus, a vibrant cross-pollination of research methodologies and research angles that have made CI into the dynamic and vibrant sub-discipline that it is today. This phase in CI research and methodology also fits in with the interdisciplinary nature of the basic paradigm shifts and with the abandonment of grand theories in favour of focussed case studies. Whilst the earlier bias of CI studies was to pinpoint interpreter error and to construct taxonomies of micro-linguistic changes in the language transferral process, many recent studies (not least the discourse analytical approach mentioned above) also highlight the micro-politics involved in the communicative event and the larger institutional constraints on the interpreter as translator and talk coordinator (in asylum hearings, for example).

The last of four Critical Link (hereafter CL) conferences held in Stockholm in 2004 could perhaps be seen as an indicator of the state of the art in CI today. CL4 (proceedings forthcoming with John Benjamins) was indeed a healthy mix of innovation, of more traditional papers on training issues, and corpus driven micro-analyses of interpreter-mediated interaction. Unlike many of their predecessors, the more recent studies on interpreter training also show awareness of how the interpreter intervenes inter- 
actively as a primary partner in the communicative event and enriches that event by his/her expert knowledge and skills. The discourse-based microlinguistic case studies show how the interpreter is 'caught' in the middle of institutional, socio-linguistic and socio-cultural demands in a wider institutional and political 'power game' or exchange of various forms of social and symbolic capital. Discussions on Codes of Ethics and Standards today show greater appreciation for culture-specificity and for the fact that such codes are idealized representations of the socio-cultural environs of its practitioners. There is also an increased awareness of the fact that such codes are situated in a wider professional and institutional field which will inevitably impact interpreter ethics and performance. This trend is a clear departure from the more static - and thus academically isolated and outdated studies in earlier CL volumes.

\subsection{Cross-cultural research and the problem of 'mediation'}

There is another aspect which is intrinsic to the nature of CI that has made it particularly amenable to the new climate, namely its cross-cultural nature. Due to the geopolitical and demographic trends of the last century, CI research often (but certainly not always) engages interlocutors across the borders of the Western world. Culture differences are inherent in any cross-cultural relationship of course (or even any cross-class relationship), but they are - at least on the surface - more marked and more visible in a Western vs. non-Western situation. Issues of institutional hegemony and power are also more pertinent here. These have led CI scholars to engage more actively in cross-cultural issues at a micro and macro level, raising awareness of both researcher's and practitioner's positioning (again, his/her 'gaze' as 'observer') and subjective interpretative practices in the communicative event. Cross-cultural case studies are a perfect vehicle by which to enact that 'defamiliarization' process described above, through which the writer repositions him/herself with respect to his/her own culture and the Other culture: a journey of critical self-discovery.

There is another issue at stake here which, as Pöchhacker says about the word 'interpret' being far more than 'semantic quibbling', namely the notion of 'mediation'. In several European countries (such as Italy and Spain) CI is known as 'language mediation', confusingly similar to the related but very different practice of '(inter)cultural mediation', active culture brokering. 'Mediating' is in fact one of the many metaphors for the process of language transferral between interlocutors from different languages and cultures, the idea being that the interlocutors are brought together and understand each other thanks to the interpreter's 'bridging function'. The negotiating act inherent in the word 'mediation' illustrates well, I believe, the paradigm clash mentioned above. On the one hand we find the expectation (by service provider and interpreter) of a process of mechanical transferral of language in which text/language, utterance, utterer, receiver and culture are monolithic entities and the integrity of the source text-utterance (and its 
immediate function) is to be respected and left inviolate. On the other hand this same process is constrained by the ephemerality and interconnectedness of only seemingly solid entities of language, text, speaker's intention, culture and not least the emergence of communicative meaning through the dialogic nature of the interaction. The emergence of communicative and pragmatic 'meaning' dialogically in the interaction between the three parties in an interpreter-mediated event seems at times to go against the grain of common logic, as being counter-intuitive. It is not, in fact, compatible with the basic premise of language transfer as it was understood in mainstream TS and IS, that of 'translating everything in ST into TT with no omissions or additions'. This problem of terminological and communicative accuracy is not easily solved because it lies at the heart of interpreter ethics, and indeed the function of translating/interpreting. It is further complicated by the fact that more than other translation and interpreting practices, CI is embedded in a socio-cultural paralinguistic institutional network which sets its own mandates and requirements, not always entirely compatible with the interpreter's primary mandate of bi-directional textual accuracy and completeness (i.e. translating the text accurately and fully to both parties in equal measure). Understandably, due to the power asymmetry between the three parties, the institution's/service providers' mandate will generally take precedence. When the interpreter finds him/herself drawn between his/her own primary mandate and a potentially conflicting one by the service provider or client, a negotiating process ensues in which (s)he is able to uphold his/her mandate following the general standards of interpreting ethics by making this clear to the interlocutors; or else (s)he may have to reach a compromise and accommodate the other parties' needs. We see then that the unique interface of institutions on the one hand (power asymmetries, client and institutional needs, the constraints of public funding and professionalization of the discipline) and academic-theoretical constraints on the other, has led CI to a unique trajectory in the evolution of academic paradigms. More than any other branch of translation, CI is embedded in a complex web of culture, language, power and institution. Without the insights from other disciplines during these last decades, it would have been difficult to understand these conflicting ethical demands upon the interpreter and to untangle this complex web.

\subsection{Research methodologies}

Rather than a set of overarching paradigmatic grand theories, CI literature today comprises a series of micro-processes, research models and strategies (empirical studies in discourse analysis, surveys, cross-cultural juxtaposition and comparison, etc.) still partly informed by earlier linguistic grand theories but sensitive to the interpreter's subjectivity, to the relativity of cultural (if not institutional) norms, to the ephemeral nature of the text and to the potential contradictions inherent in the application of these various domains. This is not to say that prescriptive studies are obsolete or theoretic- 
ally misleading: in $\mathrm{CI}$ - both as a profession and as an academic discipline - the Codes of Ethics advocated by numerous professional associations are clearly informed by an earlier prescriptive paradigm and a more mechanical view of language transfer and textual accuracy. Although potentially conflicting, I would argue that this is inevitable (or as Wagner says above, 'a necessary illusion'). For CI to be a profession in the real sense of the word, we need a training system for new practitioners. A Code of Ethics providing guidelines and 'rules' as a safety-net for future practitioners is a necessary part of a profession and of its training procedures. In a practice in which so much is potentially at stake (in a court of law, a doctor's consultancy, etc.) an interpreter cannot uncritically yield to a post-modern, deconstructionist application of textual practices, however 'true' they may be, but must respect the demands of the other interlocutors and of the institution, however 'myopic' they might be from a language-theoretical and discoursal point of view.

\subsection{Shared metaphors}

I have attempted to show here that some of the major issues marking the paradigm shift in the humanities have a great deal in common with the development of CI as a branch of TS and IS and as an institutional translational practice. Many anthropologists have used the metaphor of the anthropologist/ethnographer as an 'in-between' agent by virtue of being 'in-between' cultures and 'in-between' systems of representation (as does Wagner 1975: 10), stressing the translator-interpreter's capacities and function as a language/culture expert 'in-between' two cultures and cognizant of the premises of both, as well as the translator-interpreter's bridging/mediating function. The subjectivity and relativity of the translator-interpreter-ethnographer's capacity for objective observation and 'interpretation' has been challenged, indeed deconstructed, in anthropology, sociology, literary studies and cultural studies, as it is in the process of being deconstructed in our own discipline (i.e. the illusion of complete bi-directional cultural representation that the 'in-between' metaphor might suggest, as Inghilleri 2004 notes). The metaphor of invisibility has been thoroughly deconstructed across the board (note the studies on pronoun shifts, on changes of positioning and footing and the resulting increasing/decreasing visibility of the interpreter in the works of Angelelli, Bot and Bélanger in Brunette et. al. 2003; see also Wadensjö 1998, Roy 2000 and Angelelli 2004 a and b). The confident stand of the $19^{\text {th }}$ century scientist-observer's rational, objective analysis, him/herself a glass-like invisible non-entity rather than a filter, is no more true than the illusion of the interpreter as a conduit. We have been slow to catch on to this. Almost a century has passed since the work of the Russian formalists, of Malinowski and Boas, Peirce and a good many decades have already passed since Bourdieu (1930-2002) and Barthes (19151980). And yet, challenging the monolithic nature of text and discourse still seems novel. Empire builders in the New World were aware of what we 
seem to have forgotten - namely that interpreters should be chosen carefully, and that loyalty and power hierarchies are treacherous things that must be dealt with carefully. And, that the interpreter is far from invisible.

There is one last metaphorized premise, and a particularly delicate one, that CI is challenging (albeit often reluctantly) and that shares the concerns of the anthropologists and discourse scholars mentioned above, namely that of the sacrality and the authorship of the original text. This is precisely the paradigmatic basis that has been challenged by literary studies, particularly in the 1970s-1980s. In a dialogic interpreter-mediated communicative event between three parties, the authorship of the utterance (or the text for a translator) is challenged by the dynamics and 'micro-politics' of the dialogue. The interpreter takes control by coordinating talk, as Wadenjsö has so aptly demonstrated, and thus takes responsibility not only for the transferral of the utterance, but for its pragmatic impact in that situation. The text-utterance leaves the control of the author/speaker, and meaning emerges through a dialogical process between the three parties collectively and as a result of each of their embeddedness in a particular socio-cultural and institutional context. Language, as Wagner notes, cannot exist outside human life. It becomes meaningful when it is engaged in human relations (as Wadensjö's metaphor of the 'pas-de-trois' so eloquently evokes). The translated text loses its exclusively derivative status and acquires a new status in a negotiation process between the three parties. This process is not a free-for-all 'no holds barred, unchecked' reformulation, however, but one that is closely guided by the interpreter's ethics and conscience, by the interlocutors' needs and by the institution's mandate and needs.

\subsection{Legal interpreting and Sign Language interpreting}

There are two fields of research and practice that should have been given much more prominence in this paper, but which have for reasons of space been neglected: namely legal interpreting, in which the institutional constraints upon the interpreter are of a slightly different nature than in other forms of CI, and Sign Language (SL) interpreting. There are many excellent case-studies of interpreting in the court-room (e.g. the contributions of Hale, Jakobsen and Fowler to Brunette et al 2003 and Roberts et al 2000; Berk-Seligson's well-known study 1990), descriptive studies (Morris 1995, Colin \& Morris 1996), prescriptive guidelines (Edwards 1995, Mikkelson 2000) as well as a few on the role of the court interpreter (e.g. Ibrahim 2004), all of which tend to support a more prescriptive approach. This bias is perhaps inevitable in that the contextual, institutional constraints of the field - Court/Law - and its generally accepted authority in our society, leave little room for methodological or epistemological manoeuvring. One of the most interesting current projects in this field is the Grotius-Agis project led by Corsellis and Hertog which aims to bring about standardization of training and quality in legal interpreting and translating across Europe. Again, in projects such as this which must take into account and meet the 
demands of politicians and other decision-makers, CI practitioners and scholars can advocate an independent Code of Ethics and independent vision of the basic paradigms of the discipline only insofar as it coincides with that of the funding and decision-making institutions (EU, national courts). This illustrates very well, I believe, the unique position of CI at the interface between theory/academia and professional practice, subject to the constraints of institutional realities. This interface both constructs and limits the development of its underlying parameters and paradigms.

Even more deplorable, however, is the lack in this paper of virtually any mention of Sign Language interpreting. SL interpreting has indeed been the precursor to this entire field of study and is opening up CI to new experimental and pioneering research methods and ways of envisioning the translational process, perfectly in line with - if not ahead of - the paradigm shifts discussed in this paper. It is not incidental, I believe, that two of the contributions to the last CL conference (Turner 2004 and Kent 2004) that point to radically new possibilities in the future, come precisely from this field. In SL the interface profession-academia has been less stale and enjoyed a different sort of dynamics with respect to spoken-language CI and conference interpreting studies.

\section{Future trends...}

In his 2004 presentation, Turner proposes a new 'collaborative', 'co-production' paradigm for IS, pointing towards a future in which technology will play an increasingly important role and in which the interpreter is increasingly empowered. He argues that with increasing professionalization and the opportunities offered by new technologies, interpreters/translators will play a far more interactive and collaborative role than they have played until now - where each player is being focussed exclusively on one particular task, rather than seeing that task in a more global perspective and taking responsibility only for their own isolated 'unit of activity', as it were. At the same conference, Kent investigated the role of interpreters through the client's criticism, asking questions which many take for granted and fail to question or contextualize (for example 'standardization'). She shows how the process of professionalization is linked also to complex ideological and social factors governing its immediate socio-cultural environs - linguistic and educational policies, for example, and argues for a "re-enactment of power relations" (Kent 2004). This study embodies not only the paradigm shift described in this paper, but like Turner, she proposes a more integrated approach towards the exchange as a whole, rather than as a set of isolated tasks for each member. Thus, Kent and Turner are both bringing together the institutional constraints mentioned above with the ethical, practical and theoretical peculiarities of CI in what might turn out to be a new, and perhaps rather unexpected, paradigmatic turn. I might be going against the grain, but personally, I foresee a future in which interpreter roles are no longer defined by strictly positivist, out-dated and conservative Codes of 
Ethics that do not account for institutional- cross-cultural-, sociologicaland ideological concerns, not to mention budget, but one in which interpreters are more globally empowered and one in which the competencies of the interpreter will better match the needs of the institutions. A closer, more participatory and collaborative link between interpreters and institutions is needed, finding that common ground and interface between interpreters' services and ethics and those of the client and service providers (esp. medical and legal ethics). This could also help mend the current rift between the various parties and professions in the exchange.

As Wagner, Marcus \& Fischer note, and as Shlesinger notes in the context of IS, research paradigms often coexist side by side. Such subparadigms (or "clusters" as Pöchhacker calls them) may be complementary or in part contradictory, but nonetheless work together in creating a network of debate. Cronin (2002: 387-397) calls for a 'cultural turn' in IS. Perhaps, with CI, the new kid on the block has already met this challenge. Perhaps $\mathrm{CI}$ is leading mainstream IS by the hand into a new era of research in which the myriad of variables that constitute the complexities of language as a social, cultural, institutional and ideological practice are more fully appreciated and understood by researchers and practitioners alike, enhancing the quality of research, practice and communication with institutional representatives and decision-makers.

\section{Bibliography:}

Angelelli, Claudia (2004a). Medical Interpreting and Cross-cultural Communication. Cambridge: Cambridge University Press.

Angelelli, Claudia (2004b). Re-visiting the Role of the Interpreter: a study of conference, court and medical interpreters in Canada, Mexico and the United States. Amsterdam: John Benjamins.

Berk-Seligson, Susan (1990). The Bilingual Courtroom: Court Interpreters in the Judicial Process. London: The University of Chicago Press.

Bourdieu, Pierre (1991). Language and Symbolic Power. Cambridge: Harvard University Press.

Brunette, Louise, Georges Bastin, Isabelle Hemlin \& Heather Clarke (eds) (2003). The Critical Link 3. Interpreters in the Community. Amsterdam: John Benjamins.

Carr, Silvana et. al. (1997). The Critical Link: Interpreters in the Community. Amsterdam: John Benjamins.

Chesterman, Andrew (1997). Memes of Translation: The Spread of Ideas in Translation Theory. Amsterdam: John Benjamins.

Colin, Joan \& Morris, Ruth (1996). Interpreters in the Legal Process. Winchester: Waterside Press.

Cronin, Michael (2002). "Looking ahead". Miriam Shlesinger \& Franz Pöchhacker. The Interpreting Studies Reader. London: Routledge, 387-397.

Drennan, Gerard \& Leslie Swartz (1999). “A concept over-burdened: Institutional roles for psychiatric interpreters in post-apartheid South Africa". Interpreting 4(2), 169-198.

Edwards, Alicia (1995). The Practice of Court Interpreting. Amsterdam: John Benjamins.

Erasmus, Mabel (ed.) (1999). Liaison Interpreting in the Community. Pretoria: Van Schaik.

Hermans, Theo (1999). Translation in Systems. Descriptive and System-oriented Approaches Explained. Manchester: St. Jerome.

House, Juliane (1981). A Model for Translation Quality Assessment. Tübingen: Gunter Narr Verlag.

Hymes, Dell (ed.) (1988/1974). The Ethnography of Speaking. Cambridge: Cambridge University Press.

Ibrahim, Zubaidah (2004). "Interpreter as Advocate?" Paper presented at Critical Link 4, Stockholm, Sweden, May 2004.

Inghilleri, Moira (2004). "Encountering Voices: the Role of Interpreters in the Political Asylum Process in the U.K.”. Paper presented at Critical Link 4, Stockholm, Sweden, May 2004. 
Kaufert, Joseph M. \& Robert W. Putsch (1997). "Communication through Interpreters in Healthcare: Ethical Dilemmas Arising from Differences in Class, Culture, Language and Power". The Journal of Clinical Ethics 8(1), 71-87.

Kent, Stephanie Jo (2004). “'Why Bother?' Institutionalization, Interpreter Decisions, and Power Relations". Paper presented at Critical Link 4, Stockholm, Sweden, May 2004.

Marcus, George E. \& Fischer, Michael (1986). Anthropology as Cultural Critique. London: The University of Chicago Press.

Mason, Ian (ed.) (1999). Dialogue Interpreting (Special Issue, The Translator 5: 2). Manchester: St. Jerome Publishing.

Mason, Ian (ed.) (2001). Triadic Exchanges. Studies in Dialogue Interpreting. Manchester: St. Jerome Publishing.

Metzger, Melanie (1999). Sign Language Interpreting: Deconstructing the Myth of Neutrality. Washington: Gallaudet University Press.

Mikkelson, Holly (1996). "Community Interpreting. An emerging profession”. Interpreting 1(1), 125-129.

Mikkelson, Holly (2000). Introduction to Court Interpreting. Manchester: St. Jerome Publishing.

Morris, Ruth (1995). “The Moral Dilemmas of Court Interpreting”. The Translator 1(1), 25-46.

Pöchhacker, Franz (1999). "Getting Organized. The Evolution of Community Interpreting". Interpreting 4(1), 125-140.

Pöchhacker, Franz (2004). Introducing Interpreting Studies. London: Routledge.

Putsch, Robert (1985). "Cross-cultural Communication. The Special Case of Interpreters in Health Care". JAMA 254(23), 3344-3348.

Roberts, Roda P. et. al. (2000). The Critical Link: Interpreters in the Community. Amsterdam: John Benjamins.

Roy, Cynthia (2000). Interpreting as a Discourse Process. Oxford: Oxford University Press.

Saville-Troike, Muriel (1982). The Ethnography of Communication. An Introduction. Oxford: Basil Blackwell.

Shlesinger, Miriam \& Pöchhacker Franz (eds) (2002). The Interpreting Studies Reader. London: Routledge.

Solomon, Mildred Z. (1997). "Review of From What's Neutral to What's Meaningful: Reflections on a Study of Medical Interpreters by Kaufert and Putsch". The Journal of Clinical Ethics $8(1), 88-93$.

Toury, Gideon (1995). Descriptive Translation Studies and Beyond. Amsterdam: John Benjamins.

Turner, Graham (2004). "Professionalisation of Interpreting With the Community: Refining the Model". Paper presented at Critical Link 4, Stockholm, Sweden, May 2004.

Venuti, Lawrence (ed.) (2004). The Translation Studies Reader. London: Routledge.

Wadensjö, Cecilia (1998). Interpreting as Interaction. London: Longman.

Wagner, Roy (1981). The Invention of Culture. London: The University of Chicago Press. (first edition: 1975)

1 Such a period of suspension in between grand theories is in line with Thomas Kuhn's idea of paradigm shifts as 'revolutionary' rather than evolutionary described by Pöchhacker (Pöchhacker 2004: 67). In the same volume Pöchhacker quotes Shlesinger as saying "there are several conceptually and methodologically distinct research traditions in interpreting studies to which one may attribute paradigm status", the paradigms being interrelated with each other, and complementary" (Pöchhacker 2004: 80). Pöchhacker depicts these overlapping, interrelated (possibly 'incomplete') paradigms as "clusters", very much in line with the description of the overlapping, localized research traditions in anthropological literature.

2 There have been some efforts to revive unitary theories (e.g. Marxism) and to use them as loose frameworks within which to examine local realities or as a method of representation (see Marcus \& Fischer 1986: 11). In economics, the last major grand theory - 'Keynesian theory' - has been supplanted by the conservative neoclassical 'rational expectations' model in which the individual is assumed to be both representative and a rational decision-maker. In such disciplines, which are at the interface between soft-hard sciences as well as at the interface between academia and politics, a desire to maintain grand theories (only in part compensated for by heterodox criticism and counterapproaches) is perhaps more understandable. Of course, in an epistemologically complex discipline such as economics, there is a great deal at stake for academic theorists and institutional decisionmakers; the potentially high financial risk of proposing and implementing alternative, radical theories creates a tendency towards conservatism. Jurisprudence, also situated at the interface academia - political decision-making, has the same conservative tendency, and few scholars have openly challenged the reigning paradigms in Western law-making and legal philosophy. Diachronic and cross-cultural comparisons have come from anthropology and sociology rather than law 
faculties. Medicine, although naturally informed by biology, chemistry and physics and thus less accommodating of relativistic paradigms, is increasingly open to the cultural, ideological and crosscultural factors of medical treatment, not least in areas such as cross-cultural mental health, issues of informed consent, and bio-ethics more generally. Indeed, it is interesting that some of the earliest studies on medical interpreting challenging the positivist paradigm in CI come from medicine, psychiatry and medical sociology, not linguistics (Solomon 1997, Drennan \& Swartz 1992, Putsch 1985, Kaufert \& Putsch 1997).

3 It should be noted, however, that the relationship between critical literary theory scholars - in particular deconstructionists - and the more recent cultural studies has often been (unilaterally) antagonistic vis-à-vis anthropology, perhaps because of the enormous impact of Said's Orientalism in which anthropology, along with other Western academic and institutional cultural practices, was considered to be part of and constructive of a eurocentric hegemonic relationship with the nonWestern world.

4 It is precisely at this interface that we find the branch of literary criticism founded by Derrida a deconstruction of absolutes, a dismantling of grand theories and objective universals in favour of a relativizing not only of cultures/discourse groups but of the researcher/writer and his/her own textual product as a representation of an idea, constituting a self-reflexive meta-commentary on the subject's very tools of representation. Thus, Derrida brings together ideas that have gained currency in other disciplines, rather than actually proposing a new epistemology.

5 This does not apply across the board, necessarily. Many linguists still privilege the formal aspects of language. Even more importantly, many non-Western societies advocate an intrinsically formalist reading of language in which language has in itself innate meaning and people draw upon a fixed, even ritualistic repertoire of language tools (note the importance of naming, of spells etc., as Wagner notes (1975: 107ff)). The complex and delicate interface language-scripture-religion in Islam, Judaism and to a lesser extent Christianity is indicative of this view of language (i.e. the original text - the Quran in classical Arabic - is non-negotiable and non-mutable even at the smallest micro-linguistic level; the original written word is sacred in a very concrete sense of the word).

6 Big changes are, naturally, slow changes. A major epistemological shift tends, unsurprisingly, to follow major changes or turbulence in the global political arena, as in the interwar years of the $1920 \mathrm{~s}$ and 1930s. The 'cultural critique' phase in the $1960 \mathrm{~s}$ followed a wide range of groundbreaking political events in the West, events of which the self-same actors were highly critical (the post WWII years, Vietnam and the US, the industrial revolution, the technological revolution). As indeed all global processes, it was and is a slow process, and one that does not necessarily impact on all areas of academia (it may be hampered by political-ideological interests, for example, or by the weight of market forces; it may furthermore be limited to academia, literature and high culture without having much impact at the grassroots level or at the professionalindustrial-market level). During the 1970s and 1980s cultural criticism thus became embedded in research in a range of disciplines.

7 Although the branch of TS that has come to be known as 'descriptive studies' is often opposed to 'theory/theoretical approaches' in that it advocates empirical evidence and the analysis of local case studies (as opposed to absolutist non-contextualized 'grand theories' of translation or linguistics), that is not to say that Toury's (1995) model is not 'theoretical', quite the contrary. Indeed, his model categorizing target system norms in the context of the paradigm shift described above does actually come quite close to what is in common usage considered to be a theory, in that it suggests a certain regularity and predictability inherent in the system.

8 The work of scholars such as Chesterman (1997) (memes), Hermans (1999) (systems) and House (1981) (translation taxonomies) are perhaps closer to 'grand theories'; indeed it is not unusual for forays into grand theory to coexist alongside more localized and/or descriptive case studies. 